\title{
TUBERCULOSIS OF THE PATELLA (A CASE REPORT)
}

Ahmed Parvez, Tank Gyaneshwar, Singh Amit, Gupta Alok, Gupta Amit.
1. Associate Professor,. Department of Orthopaedics,, L.L.R.M.Medical College,Meerut, Uttar Pradesh.
2. Assistant Professor,. Department of Orthopaedics,, L.L.R.M.Medical College,Meerut, Uttar Pradesh.
3. Resident,. Department of Orthopaedics, L.L.R.M.Medical College,Meerut, Uttar Pradesh.
4. Resident,. Department of Orthopaedics, L.L.R.M.Medical College,Meerut, Uttar Pradesh.
5. Resident,. Department of Orthopaedics, L.L.R.M.Medical College,Meerut, Uttar Pradesh.

\section{CORRESPONDING AUTHOR:}

Dr. Gyaneshwar Tank,

Asst. Prof \& Head,

Dept. of Orthopaedics,

L.L.R.M. Medical College, Meerut (U.P.), India.

E-mail: gyaneshwartonk@gmail.com

ABSTRACT: Isolated involvement of patella as extra pulmonary Tuberculosis is very rare. We report a rare case of Tuberculosis patella in an eight year old baby girl She was complaining of pain, swelling and joint stiffness around her right knee. Diagnosis was based on biopsy. She was treated by surgical debridement and curettage, Anti-tubercular treatment (ATT) with early mobilization of joint.

KEYWORDS: Tuberculosis, Osteolysis, debridement and curettage, Anti-tubercular treatment (ATT)

INTRODUCTION: In Osteoarticular tuberculosis, knee joint is third most common joint involved after spine and hip joint ${ }^{1}$. Knee is affected in about eight percent of Osteoarticular Tuberculosis. Isolated involvement of patella is very uncommon with reported incidence of 0.09 to $0.15 \%$ in literature ${ }^{2}$. One rare case of patellar tuberculosis is discussed here with its clinical and radiological features.

CASE REPORT: An apparently healthy 08 year old girl child presented with complaint of pain in right knee for the last one and half month duration. Later on, she developed swelling of the right knee, limping while walking and restriction of movements of right knee. She had no constitutional symptoms and she had no previous history of tuberculosis or contact with tuberculosis patients. She belonged to low socio economic status and her parents were unable to tell about immunization status of the child.

Her general examinations of all systems were within normal limit. Her Respiratory system examination revealed bilateral clear sounds with no added sounds present. She had Antalgic gait. In the local examination of right knee swelling is present with fullness in supra-patellar and infrapatellar pouch. Patella is centrally placed and upward directed. She had restriction in right knee movement due to pain \& stiffness. Patient was not able to extend her knee beyond 20-25 degree. Knee flexion was not possible beyond 90 degree.

In laboratory investigations Hemoglobin was $9.0 \mathrm{~g} / \mathrm{dlTLC}$ of $8900 / \mathrm{mm} 3$ with lymphocytosis and ESR of $30 \mathrm{~mm}$ in first hour. Quantitative CRP showed positivity with value of $14 \mathrm{mg} / \mathrm{l} \mathrm{(>10} \mathrm{mg/l}$ significant) and Mantoux test produced $16 \mathrm{~mm}$ of induration at the end of 72 hours. Antero- 


\section{CASE REPORT}

posterior and Lateral X-ray of right knee and NCCT right knee demonstrated a lytic lesion in patella containing sequestrate.

She was treated by debridement and curettage of the right Patella. Anti-tubercular medication (Rifampicin (R), Isoniazid (H), Pyrazinamide (Z) and Ethambutol (E)) with enrichment of diet and early mobilization of joint started.

Her Histopathological report revealed Granulomatous inflammation consistent with Koch's.

DISCUSSION: The Patella is very rare site for tuberculosis. Earliest reported case in literature was by D. McCrae Aitken in 19333. According to TULI SM review of 1074 cases of osteoarticular Tuberculosis, only 90 cases $(8.3 \%)$ involving the knee, out of which only one $(0.09 \%)$ was localized in patella1. Martini and Boudjema have mentioned only one case of tuberculous osteomyelitis of the Patella in 652 cases $(0.15 \%)^{4}$.Most of cases reported were in age group of five year to fifteen years. Before the age of five years, the patella is more or less cartilaginous in nature and hence, osteomyelitis of patella usually does not manifest at that age ${ }^{5}$.Direct invasion following injury, hematogenous and local spreads from pre patellar bursitis may be routes of infection in Patella6-8.

Due to late clinical presentation, the rarity of the disease and lack of clinical suspicion make it prone to delay in diagnosis. Richter et al studied seven cases of tubercular osteomyelitis whose clinical presentation were late and infection were situated inside Patella9.Differential diagnosis of lesion in patella include tumors (e.g. Chondroblastoma, Osteoblastoma, Aneurismal bone cyst, metastatic lesion ), tumor like condition(e.g. Brown tumor ) and inflammatory lesion (e.g. Gout, pyogenic disease and osteomyelitis ) ${ }^{10}$.

Imaging studies, especially in MRI, an osteolytic lesion with a sequestrum is usually suggestive of infective pathology and absence of sclerosis and location in the para-articular region suggest tuberculosis, but it could not be used as absolute diagnostic criteria 10,11. Excisional or incisional biopsy is usually required for confirmation of disease.

In this case, early institution of anti-tubercular drugs (initial 2 months RHZE than RHZ for 16 months) after debridement and curettage of Patella had minimized the spread of disease inside the joint and produce better functional outcome with minimizing the patient morbidity. An early diagnosis followed by definite treatment is desirable in such cases, as its proximity to the knee joint. Any osteolytic lesions in the patella should always be investigated and managed with suspicion of Tuberculosis in spite of it being rare.

\section{REFERENCE:}

1. Tuli SM Tuberculosis of skeletal system. NEWDELHI Jaypee Brothers Medical Publishers. 1991

2. Dhillon MS, Rajsekhar C, Nagi ON. Tuberculosis of Patella report of a case and review of literature. knee.1995;2: 53-56.

3. Tuberculosis of the Patella - D McCrae Aitken (FRCS) proceedings 1933;26:1338 (Sect. orthop.72)

4. Martini M, Boudjema A. Tuberculous osteomyelitis. In Martini M. Tuberculosis of the Bones and Joints. Berlin: Springer Verlag 1988,p,78-9

5. Moore T. Acute osteomyelitis of the patella Lancet 1938;i;552-3

6. Roy D.R. Osteomyelitis of the patella. Clin Orthop2001;389:30-4 
7. Vaninbroukx J, Martens M, Verhelst M, Mulier J C. Haematogenous osteomyelitis of the patella report of three cases. Acta Orthop Scand 1976;47:566-9

8. Evans DK. Osteomyelitis of the Patella. JBJS 1962; 44B:319-23.

9. Richter R, Herceg K, Kohler G The patellar focus, a rare form of localization of bone tuberculosis (Article in German) Z Orthop Ihre Grenzgeb 1982;120:5-9

10. Roop singh, Rakesh gupta Tuberculosis of Patella -A case report. Indian journal of orthopedics $2004 ; 38(3): 189-90$.

11. Vijay K. Agrawal, R.G. Agrawal Tuberculosis of Patella in an immunocompetent patient-a case report Indian J. Tuberc 2011 Jan,58(1)29-31

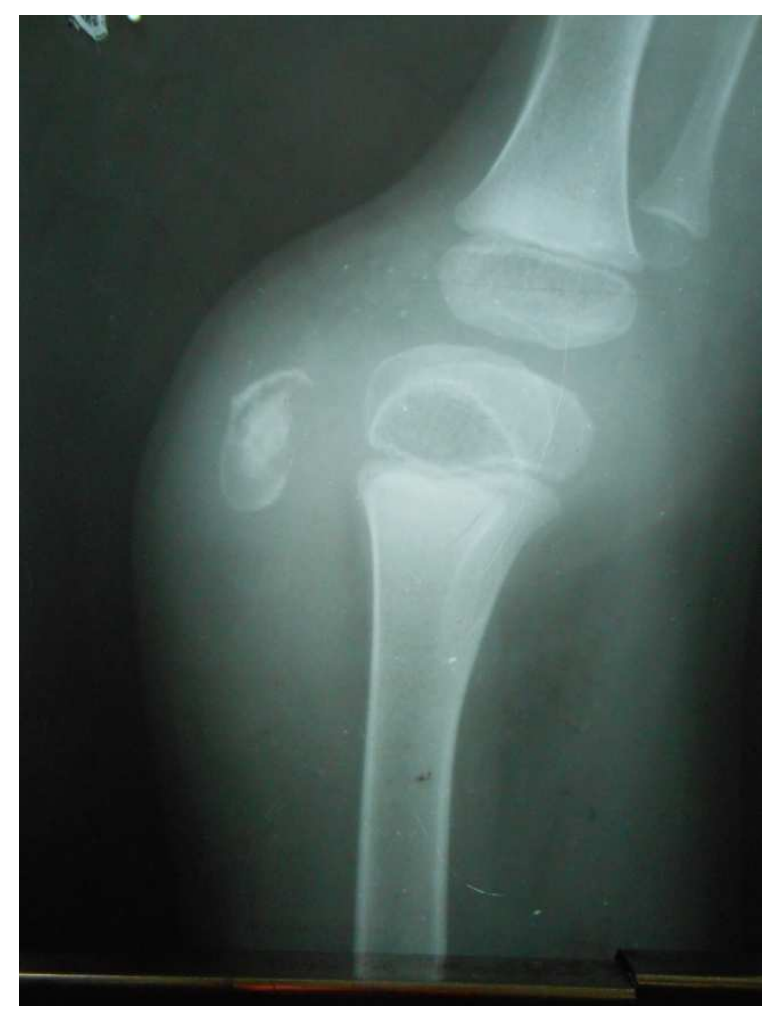

X- ray: lateral view right knee (pre-op) (osteolytic lesion in patella) 


\section{CASE REPORT}

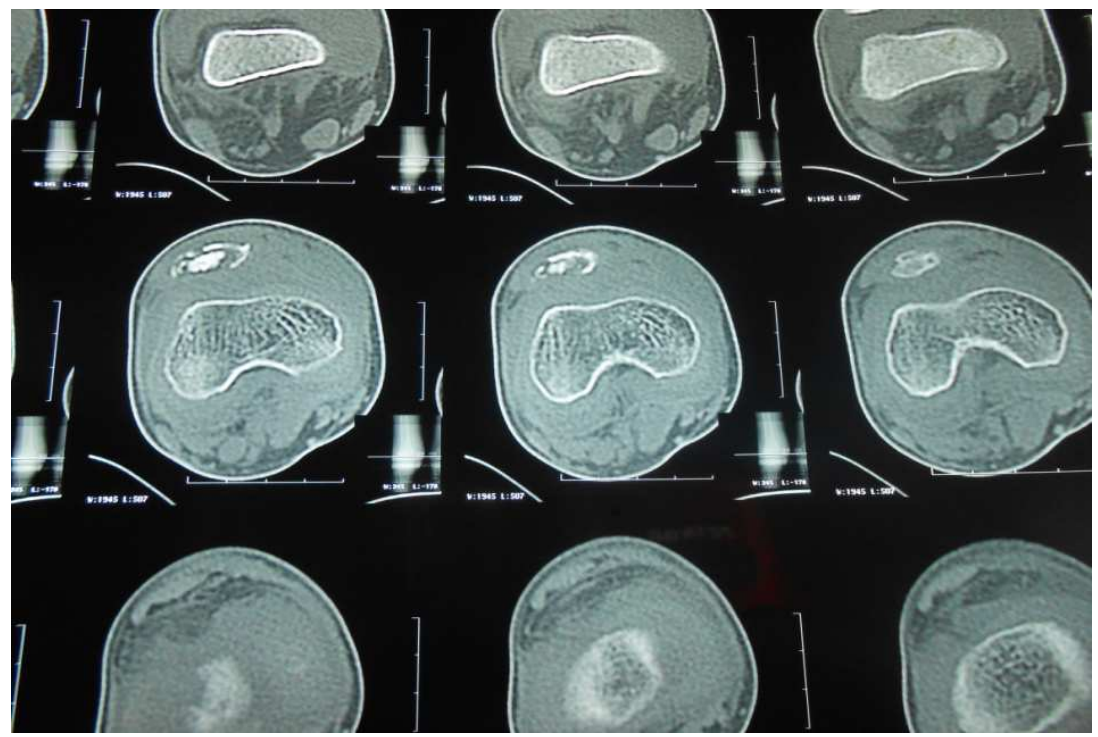

CT right knee (pre-op) (osteolytic lesion with sequestrum in patella)

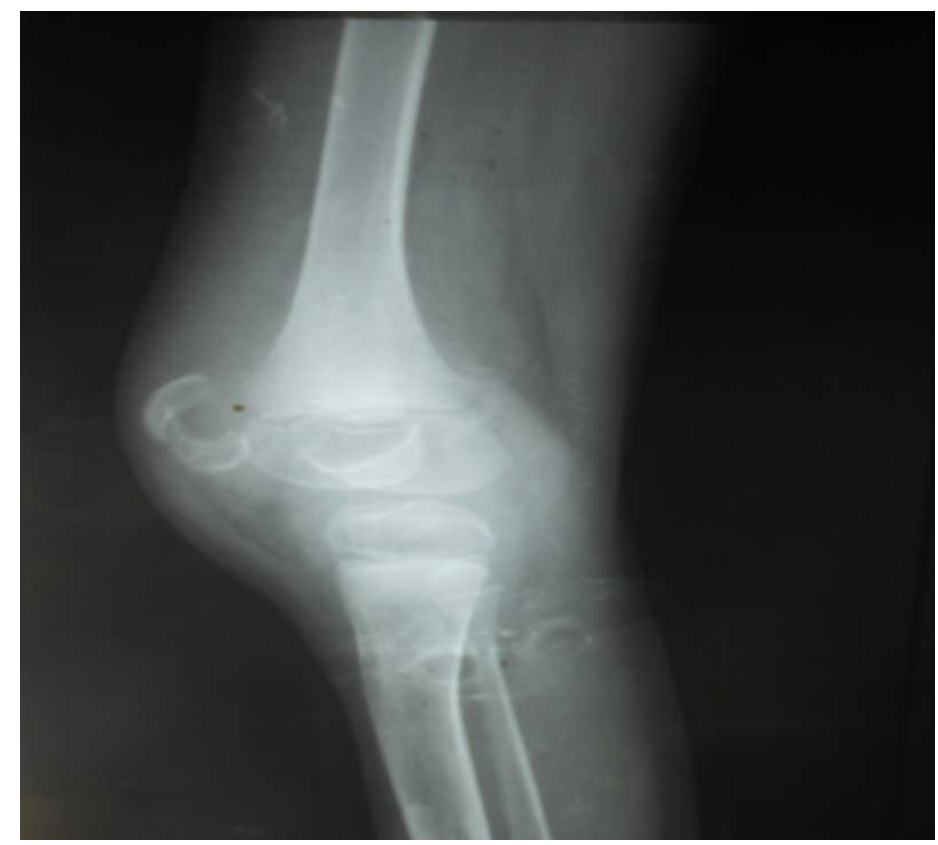

Lateral view of right knee (post-op) (after debridement and curettage) 


\section{CASE REPORT}

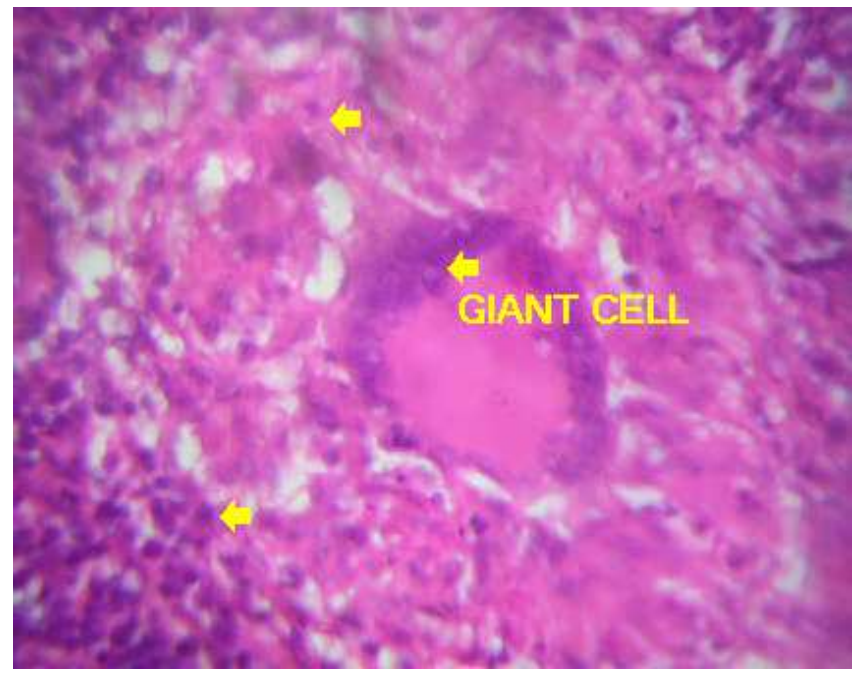

Biopsy histology shows giant cell of tuberculosis

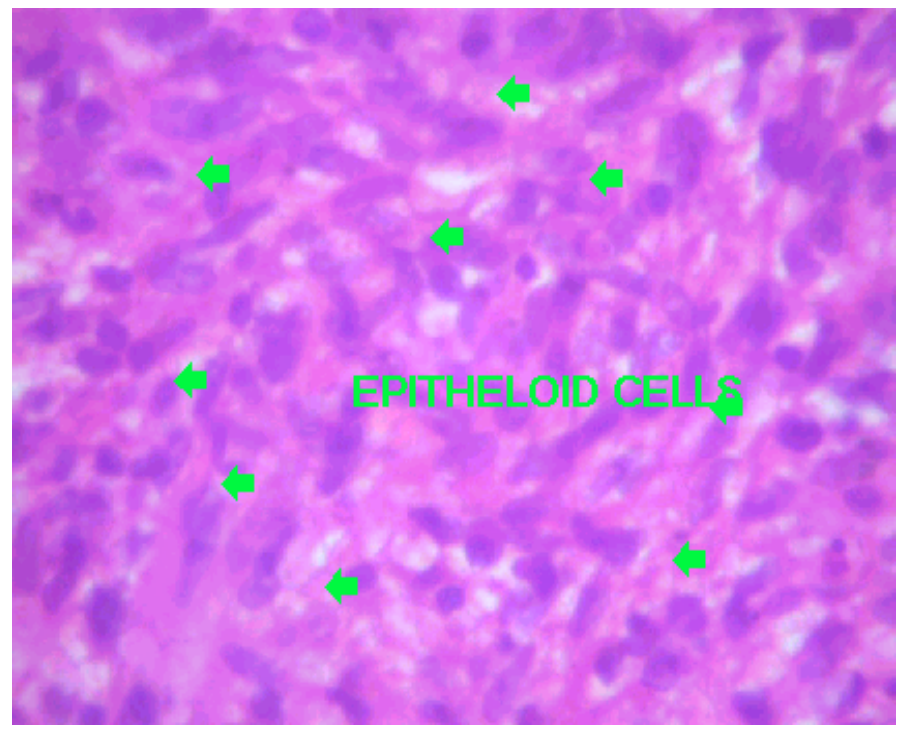

Biopsy histology shows epitheloid cell of tuberculosis 